\title{
Combined transplantation of neural precursor cells and olfactory ensheathing cells for the treatment of X-linked adrenoleukodystrophy in children
}

This article was published in the following Dove Press journal:

Journal of Neurorestoratology

18 April 2017

Number of times this article has been viewed

\author{
Hui Yangl,* \\ Yu Zhang ${ }^{1, *}$ \\ Zhaoyan Wang' \\ Wei Lu' \\ Fang Liu' \\ $\mathrm{Xin} \mathrm{Yu}^{2}$ \\ Xiaoyan Zheng' \\ Yinxiang Yang' \\ Zuo Luan' \\ Suqing $\mathrm{Qu}^{\prime}$ \\ 'Department of Pediatrics, \\ ${ }^{2}$ Department of Neurological Surgery, \\ Navy General Hospital, Beijing, \\ People's Republic of China \\ * These authors contributed equally \\ to this work.
}

\begin{abstract}
Hematopoietic stem cell transplantation is only suitable for early-stage adrenoleukodystrophy (ALD). In this study, we observed the therapeutic efficacy of combined transplantation of neural precursor cells (NPCs) and olfactory ensheathing cells (OECs) on late-stage X-linked ALD in nine children who were admitted in our hospital between June 2009 and January 2014. Related patient information included onset time 3 months to 1 year, magnetic resonance imaging (MRI) score 11.02 \pm 0.90 , and neurologic function score $2-3$. All patients received combined transplantation of NPCs and OECs by injection around the lateral angle of the frontotemporal-occipital lesion under MRI guidance. It was found that the visual function, sleep, and communication obstacles were improved significantly without evidence of disease progression in six $(66.7 \%)$ of the nine patients within 1 month after transplantation. In two of the six patients, the lesions became significantly smaller than before, although their MRI scores remained unchanged significantly. In addition, cell therapy did not induce any irreversible adverse event during the study period, indicating that combined transplantation of NPCs and OECs was safe and reliable, and could improve the clinical manifestations of ALD in children within a short time. Although this cell therapy was not able to halt the progression of the disease 1-3 months after transplantation, it could still be used as an early treatment and provide patients with more opportunities for hematopoietic stem cell transplantation, which is the only effective long-term treatment for X-linked ALD at present. The preliminary results from this study suggest that a comprehensive prevention strategy of serial and combined transplantation may improve some functions for ALD patients in the short-term, however, long-term effects need further study.

Keywords: X-linked adrenoleukodystrophy, combined transplantation, neural precursor cells, olfactory ensheathing cells
\end{abstract}

\section{Introduction}

Adrenoleukodystrophy (ALD), one of the most common peroxisomal diseases, is an $\mathrm{X}$-linked recessive genetic disease affecting $\sim 1$ in 21,000 males. The prevalence of ALD in females is $\sim 1$ in $14,000 .{ }^{1}$ ALD results from dysfunction of the peroxisomal membrane-bound ALD protein (ALDP). ALDP, which is coded by the $A B C D 1$ gene at $\mathrm{Xq} 28$, participates in the transport of cytosolic very long-chain fatty acids (VLCFAs) into the peroxisome for homeostatic oxidation. Without normal function of ALDP, VLCFAs would accumulate in tissues and circulating plasma, leading to rapid and profound neurologic decline and abnormal physical symptoms due to demyelination within the cerebral white matter. ${ }^{2}$

ALD is a rapidly progressive inherited metabolic disease with poor prognosis, the natural course of which is $2-4$ years. According to onset age, involved sites, and 
the rate of progression, ALD is roughly classified into seven types: 1) childhood cerebral form (CALD), 2) young age form, 3) adrenomyeloneuropathy type, 4) adult cerebral form, 5) olive pontine cerebellar form, 6) Addison's disease alone, and 7) non-symptom type. Childhood CALD is the form most severely involving the central nervous system (CNS). ${ }^{3}$ About $80 \%$ of ALD patients develop neurologic involvement. ${ }^{4}$ The most severe clinical manifestation of ALD is the cerebral variant (CALD), especially for childhood CALD patients. ${ }^{5}$ Childhood-onset CALD refers to onset before the age of 10 years, and the common age of onset is 4-8 years. The manifestations of childhood-onset CALD are progressive cognitive and behavioral disorders and other nervous system abnormalities. Early signs and symptoms that may arouse the attention of parents include hyperactivity with decreased attentiveness and declining school performance. Subsequently, gait abnormality, hearing and language barriers, visual anomaly, and occasional seizures appear gradually. Some patients also have symptoms of adrenal insufficiency, as represented by increased skin pigmentation, easy fatigue, and abnormal results of blood adrenocorticotropic hormone and cortisol rhythm examination. CALD progresses rapidly. Just within a few years, patients may experience complete loss of vision, hearing and language functions, and a state of generalized muscular rigidity, resulting in bed confinement for the rest of their life. Eventually, systemic failure and pulmonary infection lead to ensuing death. ${ }^{6}$

Early diagnosis and timely hematopoietic stem cell transplantation (HSCT) are the only ways to improve long-term survival of CALD patients at present. ${ }^{7}$ However, children without a clear familial history of CALD often miss opportunities for transplantation due to obvious nervous system damage during disease progression, when admitted to hospital. In addition, other current treatments such as Lorenzo oil and rehabilitation cannot improve the prognosis. In this study, we observed for the first time the therapeutic efficacy of combined transplantation of neural precursor cells (NPCs) and olfactory ensheathing cells (OECs) on late-stage X-linked ALD in nine children who were admitted in our hospital between June 2009 and January 2014 but not suitable for HSCT. The short- and long-term efficacy and safety of NSCs and OECs combined transplantation were evaluated by magnetic resonance imaging (MRI) score and neurological function score (NFS). ${ }^{8}$

\section{Patients and methods}

\section{Baseline data}

Included in this study were nine pediatric ALD patients (age of onset $7.57 \pm 1.86$ years; time of onset $6.50 \pm 3.39$ months) who received treatment in the Department of Pediatrics of our hospital between June 2009 and June 2012. Clinical manifestations were declined vision and hearing, unstable walking, communication obstacles, and decreased learning performance at the time of diagnosis. The interval from disease onset to the treatment was 3 months to 1 year. Neurologic function was evaluated by senior neurologists of the hospital prior to transplantation, including vision, hearing, motor skills, communication, and the presence or absence of urinary and fecal incontinence, and febrile convulsion. ${ }^{9}$ NFS 2-3 was defined as hearing impairment, vision loss, and walking difficulty.

\section{Diagnostic criteria}

The pattern and extent of cerebral demyelination were evaluated by brain MRI according to Daniel J MRI criteria, ${ }^{10}$ and the mean score was $11.02 \pm 0.90$. In addition, all patients received plasma VLCFAs analysis and $A B C D 1$ gene diagnosis (Table 1).

\section{Inclusion criteria}

All nine pediatric patients presented the clinical symptoms and signs of ALD before the initial diagnosis. NFS was $>1$, and the MRI score (indicating severity) was $>10$ in all nine patients.

\section{Acquisition of transplanted cells}

NPCs (Figure 1) were isolated from the cortex of voluntary donations of aborted embryos and cultured as described previously. ${ }^{11}$ Quality control of NPCs was conducted in the following areas: 1) cell morphology (suspended spherical with a diameter $<100 \mu \mathrm{m}), 2$ ) cell phenotype (99\% cells expressing nesting), 3) differentiation ability (differentiating into neurons, astrocytes, and oligodendrocytes after induction in vitro), 4) cell viability (not $<95 \%$ ), 5) microbiological detection (without bacteria, fungi, mycoplasma, hepatitis B virus (HBV), hepatitis $\mathrm{C}$ virus (HCV), human immunodeficiency virus (HIV), cytomegalovirus (CMV), Epstein-Barr virus (EBV), syphilis, and other pollutions), 6) endotoxin detection ( $<2 \mathrm{EU} / \mathrm{mL})$, and 7) karyotype (without chromosomal aberrations).

\section{Olfactory ensheathing cells}

OECs (Figure 2) were isolated from the olfactory bulbs, and cultured and identified as described by Liu et al. ${ }^{12}$ The olfactory bulbs were obtained from voluntarily donated human fetuses aged 4 months postconception. Quality control of OECs before clinical application included the following: 1) phenotype ( $>90 \%$ cells expressing P75NTR), 2) cell viability (not <95\%), 3) microbiological detection (without 
Table I Patient demographics at the time of cell transplantation

\begin{tabular}{|c|c|c|c|c|c|c|c|}
\hline $\begin{array}{l}\text { Case } \\
\text { number }\end{array}$ & $\begin{array}{l}\text { Onset age } \\
\text { (months) }\end{array}$ & $\begin{array}{l}\text { Onset time } \\
\text { (months) }\end{array}$ & NFS & MRI score & VLCFAs & Vision examination & $\begin{array}{l}\text { Threshold of binaural } \\
\text { response to short } \\
\text { duration sound }(\mathrm{dB}) \\
\end{array}$ \\
\hline I & 61 & 0.5 & 2 & 10 & $\begin{array}{l}\mathrm{C} 26: 1.3 \mathrm{mg} / \mathrm{L} \\
\mathrm{C} 24 / \mathrm{C} 22: 1.8 \\
\mathrm{C} 26 / \mathrm{C} 22: 0.17\end{array}$ & $\begin{array}{l}\text { Decreased visual acuity } \\
\text { Tubular field } \\
\text { Binocular PI00 extension }\end{array}$ & 50 \\
\hline 2 & 123 & 6 & 3 & 12 & $\begin{array}{l}\mathrm{C} 26: 3.36 \mathrm{mg} / \mathrm{L} \\
\mathrm{C} 24 / \mathrm{C} 22: 1.8 \\
\mathrm{C} 26 / \mathrm{C} 22: 0.096\end{array}$ & $\begin{array}{l}\text { Decreased visual acuity } \\
\text { Tubular field } \\
\text { Binocular PI00 extension }\end{array}$ & 55 \\
\hline 3 & 108 & 7 & 3 & 12 & $\begin{array}{l}\text { C26: } 1.95 \mathrm{mg} / \mathrm{L} \\
\text { C24/C22: } 2.1 \\
\text { C26/C22: } 0.18\end{array}$ & $\begin{array}{l}\text { No light perception } \\
\text { Binocular PI00 extension }\end{array}$ & 40 \\
\hline 4 & 91 & 7 & 2 & 11 & $\begin{array}{l}\text { C26: } 2.2 \mathrm{mg} / \mathrm{L} \\
\text { C24/C22: } 2.1 \\
\text { C26/C22: } 0.16\end{array}$ & $\begin{array}{l}\text { Decreased visual acuity } \\
\text { Tubular field } \\
\text { Binocular PI00 extension }\end{array}$ & 30 \\
\hline 5 & 107 & 12 & 3 & 11 & $\begin{array}{l}\text { C26: I.7I mg/L } \\
\text { C24/C22: } 1.9 \\
\text { C26/C22: } 0.15\end{array}$ & $\begin{array}{l}\text { Decreased visual acuity } \\
\text { Tubular field } \\
\text { Binocular PI00 extension }\end{array}$ & 50 \\
\hline 6 & 90 & 3 & 2 & 12 & $\begin{array}{l}\text { C26: I.22 mg/L } \\
\text { C24/C22: } 2.10 \\
\text { C26/C22: } 0.09\end{array}$ & $\begin{array}{l}\text { Decreased visual acuity } \\
\text { Tubular field } \\
\text { Binocular PI00 extension }\end{array}$ & 40 \\
\hline 7 & 102 & 6 & 2 & 10 & $\begin{array}{l}\text { C26: } 1.09 \mathrm{mg} / \mathrm{L} \\
\text { C24/C22: } 1.85 \\
\text { C26/C22: } 0.11\end{array}$ & $\begin{array}{l}\text { Prolonged binocular PI00 } \\
\text { latency }\end{array}$ & 50 \\
\hline 8 & 55 & 7 & 2 & II & $\begin{array}{l}\text { C26: } 1.03 \mathrm{mg} / \mathrm{L} \\
\text { C24/C22: } 2.38 \\
\text { C26/C22: } 0.11\end{array}$ & $\begin{array}{l}\text { Decreased visual acuity } \\
\text { Tubular field } \\
\text { Binocular PI00 extension }\end{array}$ & 50 \\
\hline 9 & 81 & 10 & 2 & 10 & $\begin{array}{l}\text { C26: } 1.79 \mathrm{mg} / \mathrm{L} \\
\text { C24/C22: } 1.9 \\
\text { C26/C22: } 0.17\end{array}$ & $\begin{array}{l}\text { Decreased visual acuity } \\
\text { Tubular field } \\
\text { Binocular PI00 extension }\end{array}$ & 40 \\
\hline
\end{tabular}

Abbreviations: MRI, magnetic resonance imaging; NFS, neurological function score; VLCFAs, very long chain fatty acids.

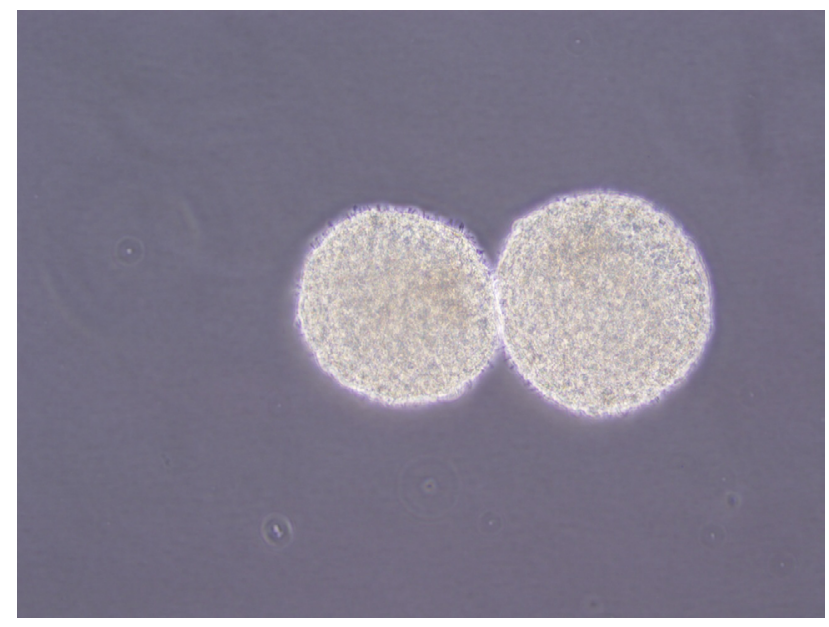

Figure I The morphology of neurosphere (magnification $\times 100)$.

bacteria, fungi, mycoplasma, HBV, HCV, HIV, CMV, EBV, syphilis, and other pollutions), and 4) endotoxin detection $(<2 \mathrm{EU} / \mathrm{mL})$.

\section{Cell transplantation}

All the nine pediatric patients received preoperative examinations including blood routine; blood coagulation;

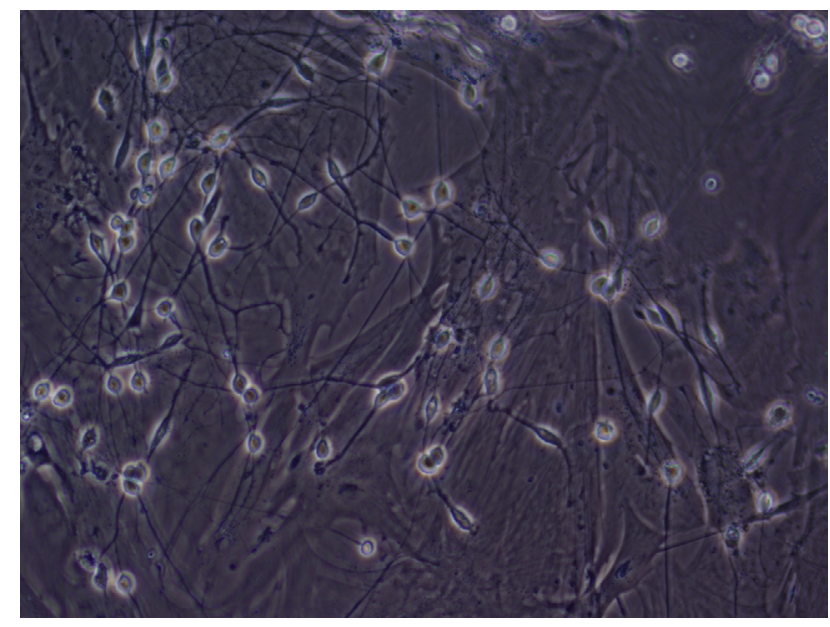

Figure 2 Cultured olfactory ensheathing cells (magnification $\times 200$ ).

immunological examinations including hepatitis $\mathrm{B}$, hepatitis C, syphilis, and AIDS; blood biochemistry; electrocardiography, chest X-ray radiography, and electroencephalography. There was no contraindication for cell transplantation in all patients, and their parents or legal guardians signed informed consent for the planned cell transplantation. After preoperative skin preparation and ketamine basal anesthesia, MRI 
was used to locate the position of the bilateral occipital lobes, temporal lobes, and the outer boundary of the lesion. The lateral angle of the frontotemporal-occipital lesion was chosen as the puncture point. Within the disinfected area, cranial drilling was performed to create holes in the skull. A transfixion pin was placed vertical to the skull before puncturing into the located position. After completing slow injection of OECs $\left(1.0 \times 10^{7} / 0.2 \mathrm{~mL}\right)$ and NPCs $\left(7.0 \times 10^{6} / 0.2 \mathrm{~mL}\right)$, the needle was withdrawn and the surgical area was pressure dressed. After transplantation, the patient was advised to lie flat on the back for $>20 \mathrm{~h}$, during which vital signs were monitored closely.

The protocol of this clinical study including cell sources was approved by the Scientific Council and Ethics Committee of the Navy General Hospital and was in accordance with the guidelines issued by the Chinese Ministry of Health (91-006). ${ }^{13}$ The parents or guardians of the patients were fully informed about the sources, separation and cultivation of the transplanted cells, methods of cell therapy, risks of the surgery, possible adverse effects, and safety measures and they all provided written informed consent for both the procedure and inclusion in this study. All treatment procedures were under the supervision of the Ethics Committee of the hospital.

\section{Outcome evaluation}

Preoperative evaluation included hearing and auditoryevoked potential, vision and visually evoked potential, video electroencephalogram, intelligence, movement, and neurological examination. At the same time, changes in sleep, diet, mood, vision, hearing, and communication were recorded. After transplantation, patients were observed in the hospital for a month and then followed up for 6 months to 2 years after discharge.

Valid criteria/effectiveness standards included: 1) improvement of the clinical manifestations, 2) the state of disease progression within 3 months after transplantation, and 3) change in the size of the lesion as shown by MRI scanning.

\section{Results}

The clinical manifestations were improved significantly in six $(66.7 \%)$ of the nine patients in 5 days to 1 month after transplantation, including hearing improvement in one, vision improvement in two, communication and memory improvement in two, and even lesion shrinkage in two of the six patients.

The patient in Case 1 exhibited hearing improvement and steady walking from day 5 to 30 after transplantation, although his vision and communication showed no significant improvement. However, 1 month after cell therapy, the hearing and walking abilities fell to the level before transplantation or even aggravated. Two months after transplantation, repeated MRI brain scan showed that the long T2 signal of the optic nerve became weakened, and the left parietal long T2 signal range was decreased obviously (Figures 3 and 4).

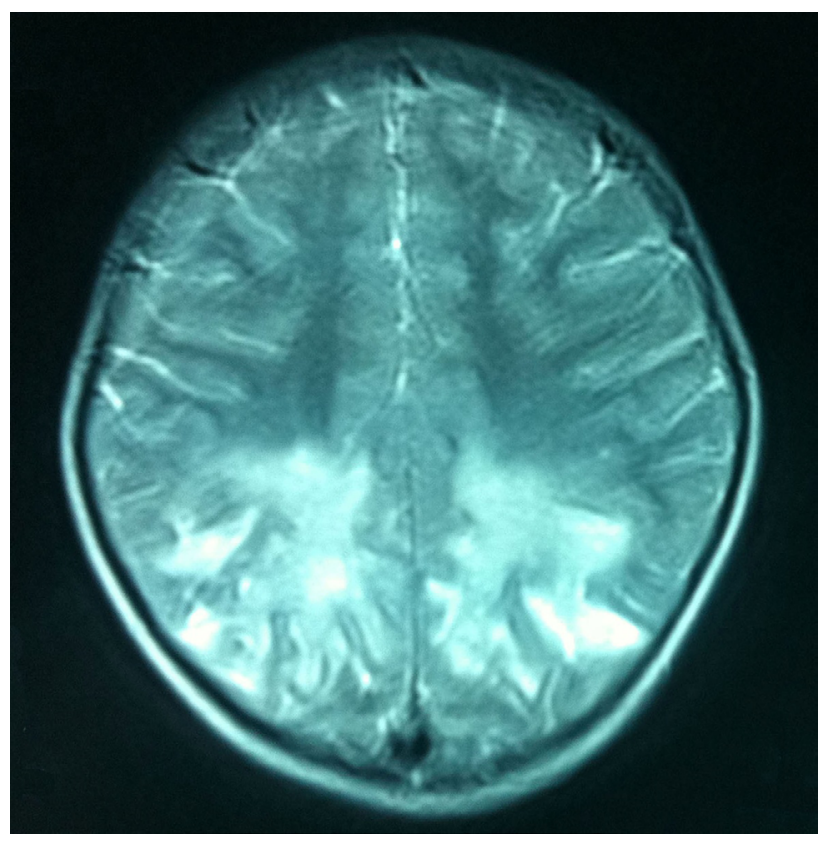

Figure 3 Preoperative long T2 signals of the bilateral occipital lobe and optic nerve on MR image before transplantation.

Abbreviation: MR, magnetic resonance.

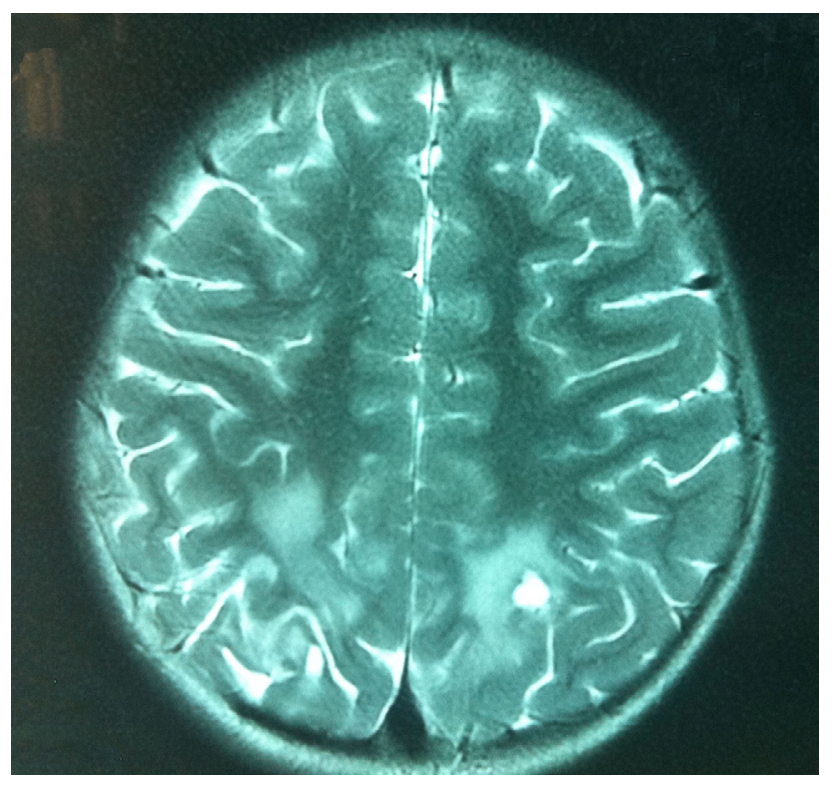

Figure 4 Repeated MR images after cell therapy. The long T2 signal of the bilateral optic nerve became weakened, and the range of left parietal long T2 signal was decreased.

Abbreviation: MR, magnetic resonance. 
Table 2 Changes in clinical manifestations, MRI signals, hearing, and vision after cell transplantation

\begin{tabular}{|c|c|c|c|c|}
\hline $\begin{array}{l}\text { Case } \\
\text { number }\end{array}$ & Clinical manifestation & MRI signal & Vision examination & $\begin{array}{l}\text { Binaural response to } \\
\text { short-duration sound }\end{array}$ \\
\hline $\mathrm{I}$ & $\begin{array}{l}\text { Improved hearing and } \\
\text { steadier walking }\end{array}$ & $\begin{array}{l}\text { Weakened long T2 signal of optic } \\
\text { nerve } \\
\text { Obviously decreased range of left } \\
\text { parietal long T2 signal }\end{array}$ & No change & Decreased threshold \\
\hline 2 & $\begin{array}{l}\text { Improved memory, } \\
\text { strengthened walking, } \\
\text { increased visual acuity, and } \\
\text { ability to avoid obstacles }\end{array}$ & $\begin{array}{l}\text { Weakened long T2 signal of bilateral, } \\
\text { parietal, and occipital white matter } \\
\text { (surrounding lesions-based) }\end{array}$ & $\begin{array}{l}\text { Increased visual acuity and } \\
\text { field }\end{array}$ & No change \\
\hline 3 & Improved quality of sleep & No change & No change & No change \\
\hline 4 & No obvious change & No change & No change & No change \\
\hline 5 & $\begin{array}{l}\text { Increased visual acuity and } \\
\text { improved communication ability }\end{array}$ & No change & Increased visual field & No change \\
\hline 6 & $\begin{array}{l}\text { Increased visual acuity and } \\
\text { amount of talking }\end{array}$ & No change & Increased visual field & No change \\
\hline 7 & $\begin{array}{l}\text { Increased visual acuity and } \\
\text { unsteady walking }\end{array}$ & No change & Decreased visual field & No change \\
\hline 8 & $\begin{array}{l}\text { Improved ability of } \\
\text { communication and increased } \\
\text { amount of talking }\end{array}$ & No change & No change & Increased threshold \\
\hline 9 & Decreased hearing & No change & No change & Increased threshold \\
\hline
\end{tabular}

Abbreviation: MRI, magnetic resonance imaging.

The patient in Case 2 exhibited improvement in memory as represented by the ability of remembering the phone numbers more quickly, walking as represented by being more energetic or even being able to run, and vision as represented by being able to avoid obstacles and discern steps during walking, when compared with their preoperative conditions. Twenty days after transplantation, repeated MRI brain showed that the long T2 signal of the bilateral, parietal, and occipital white matter became weakened, and the signal range was also decreased.

The patient in Case 3 exhibited obvious sleep improvement 1 week after cell therapy. His eyesight and hearing obstacles did not progress within a month but then became worse than the condition before treatment.

The patient in Case 5 showed improvement in eyesight and communication 10 days after surgery. He could recognize the shape of objects in the air and had proactive requirement language.

The patient in Case 6 showed improvement in eyesight as represented by being able to watch television $\sim 1$ week after treatment. His proactive language was also increased.

The patient in Case 8 showed improvement in communication with the outside world. His proactive language was also increased.

NFS and MRI scores remained unchanged significantly after treatment in all nine patients, although the lesions became smaller in Cases 1 and 2. The conditions of Cases 4, 7, and 9 patients progressed to some extent during hospitalization
(Table 2). All the nine patients were retained in the hospital for a month for further observation and then followed up for 3 months by telephone after discharge. All the nine patients experienced varying degrees of disease progression during the 1- to 3-month follow-up periods after transplantation. Although four patients failed to respond to the cell therapy and died 2-3 years after the onset of disease, no death occurred during the follow-up periods.

No serious irreversible procedure-related adverse events occurred during the follow-up periods in any of the nine patients.

\section{Discussion}

All nine cases in this study belong to childhood CALD. There is no specific drug for the treatment of this disease at present. Hormone replacement therapy is the only mainstay treatment for pediatric ALD patients who have functional abnormalities involving the adrenal cortex.${ }^{14}$ Dietary Lorenzo oil therapy is another option, but it is suitable only for two types of ALD patients: patients with no nerve disease and normal cranial MRI, and those with adrenal myelopathy type alone. Lorenzo oil can delay the progression of the disease in patients with the latter type but not in patients with the former type. ${ }^{15}$ In addition, some studies suggested that HSCT could increase long-term survival of ALD patients, regardless of bone marrow or cord blood HSCT. However, HSCT needs to be conducted in the early stage of the disease with 
an NSF score of $<1$ and an MRI severity score of $<9$ in the 34-point scoring system designed by Loes et al. ${ }^{10}$ Given the above conditions, the 5-year survival rate for such patients can reach $92 \%$. According to a single-center study of HSCT in 60 patients with childhood CALD conducted by the University of Minnesota, ${ }^{16}$ evaluation of MRI severity before HSCT is primarily important. Score 10 is the margin because it is related to the therapeutic efficacy. The NFS also has great impact on the long-term survival rate. It was reported that the long-term survival rate was $25 \%$ lower in children with an NFS of $>1$, when compared with that in children with an NFS of 0 . Because of its insidious onset and no popular inherited metabolic screening for ALD due to existing constraints, the diagnosis of this disease was usually delayed and, therefore, the patients often missed the best opportunity for effective allo-HSCT therapy. Most of these childhood patients already had at least one to two neurological damages at the first visit to a doctor, when their white matter damage had already shifted into the "acceleration" phase. Thus, it is essential to fight chance for effective HSCT therapy and seek new treatment for these childhood patients.

A series of studies on NPC transplantation for childhood patients with various CNS diseases has been conducted in our pediatrics center since 2005. Both animal experiments and clinical trials have demonstrated that NPC treatment is safe and effective for cerebral palsy (in animal models), neonatal hypoxic ischemic brain damage, and neonatal critical carbon monoxide poisoning. ${ }^{17-19}$ An American clinical study ${ }^{20}$ also confirmed that the use of fetal brain-derived NPC was safe in the treatment of Batten disease. In addition, both long-term survival of transplanted NPC and survival rates of these patients were increased.

Although no data concerning the clinical research of NPC transplantation for the treatment of X-linked ALD have been reported in the literature, multiple animal experiments or clinical trials have demonstrated the feasibility of NPC or genetically modified NPC on other neurological diseases and injury-associated metabolic disorders, including neuronal ceroid lipofuscinoses (NCLs), ${ }^{21}$ Niemann-Pick diseases (sphingomyelin lipidosis), ${ }^{22}$ and spherical leukodystrophy. ${ }^{23}$ A clinical study conducted by Selden et al suggested that allogenic human NPC transplantation via the cerebral hemisphere and lateral ventricle could reduce storage substances accumulated in the brain of six infants or late baby with NCLs through producing palmitoyl-protein thioesterase 1 and dipeptidyl peptidase $1 .{ }^{24}$ No transplantation-related severe adverse events occurred during the study. Shihabuddin et $\mathrm{al}^{22}$ found that many sites within the brain transplantation of adult mouse NPC with the overexpressed acid sphingomyelinase gene (ASM) into the Niemann-Pick-A mouse (ASM gene knocked out) led to a marked regional decrease in free cholesterol and sphingomyelin storage. These NPCs could survive for as long as 10 weeks and their migration also occurred.

Currently, NPCs have been used to treat animal models of other types of leukodystrophy, metachromatic leukodystrophy, and globoid cell leukodystrophy. ${ }^{23,24}$ The results suggest that NPC could attenuate damage to motor functions. Transplanted mouse NPC or gene-modified NPC (overexpressed $\beta$-galactocerebrosidase [GALC]) could survive for a long time in the brain of a globoid cell leukodystrophy mouse model, produce functional GALC and enhance the enzyme activity in the brain and spinal cord, reduce accumulation of galactocerebroside, delay symptom onset, and extend their life spans to 2-3 times longer than expected. In addition, these transplanted NPC had a substitution effect on oligodendrocytes and a remyelination effect. ${ }^{24,25}$ All these studies demonstrated that NPC had the abilities of migration, regional-specific differentiation, removing various accumulations in the brain and reducing damage to motor functions, suggesting the potential of NPC in the clinical treatment of ALD and the possibility of its restorative effect at some level.

In recent years, OEC transplantation is a hot research area in neurorestorotherapy, and one of the most potential treatments for repairing CNS diseases, including spinal cord injury, amyotrophic lateral sclerosis, stroke, and multiple sclerosis. ${ }^{26-30}$ Mackay-Sim et al demonstrated the feasibility of using autologous OEC transplantation for the treatment of spinal cord injury in six patients and at least 3-year safety post-implantation. ${ }^{29}$ In addition, OEC transplantation could improve light touch and pin prick sensitivity over three segments, and no significant complication and tumor formation occurred. OEC as a type of glial cells that have dual differentiation fates can differentiate into Schwann cells and oligodendrocytes. Compared with Schwann cells or oligodendrocytes, OEC can improve axonal regeneration and have a myelinization effect. ${ }^{31}$ Shi et al evaluated the repair effect of OEC on white matter damage in rats undergoing middle cerebral artery occlusion. On day 56 after transplantation, OEC reduced the infarct volume, decreased mortality, and improved remyelination and axon regeneration of the white matter lesions. ${ }^{32}$ Apart from direct participation in myelination, OEC could secrete various neurotrophic factors including NGF, BDNF, N73/4, and GDNF, inhibit the secretion of harmful factors, and promote neural regeneration, 
growth, and differentiation. ${ }^{33,34}$ In addition, co-culture of OEC with NPC could significantly promote differentiation of NSC and axon elongation. ${ }^{35}$ Multiple animal experiments also suggested that combined transplantation of NPC and OEC generated better performances in treating various neurological injuries, including spinal cord injury and traumatic brain injury. Better motor function or cognitive function, much less apoptosis, and the higher number of neurons differentiating from NPC were observed in the combined transplantation group, compared with single NPC or OEC transplantation group. ${ }^{36-38}$

However, the efficiency of the combined transplantation on ALD and other inherited metabolic diseases has not been demonstrated. The remedial effect of single NPC transplantation on multiple inherited metabolic diseases has been well documented. In addition, the growth and differentiation of NPC can be promoted by OEC, and meanwhile OEC itself has the abilities of axonal regeneration and remyelination. With all these observations taken into account, we hope that the combined transplantation of NPC and OEC could provide a new idea and mean for the treatment of ALD. All nine childhood patients included in this study already had at least two neurological damages at the first visit to the doctor, in whom the NFS was $>2$ and the MRI severity score was 10-12. The main clinical symptoms and signs in these patients were declined eyesight, damaged hearing ability, and unstable walking. Their medical histories suggest that some patients also had communication obstacles, declined memory, decreased learning performance, and skew writing in the beginning of the disease. MRI scan showed significant matter lesions in these patients. Seeing that they all had missed the chance for effective cure by HSCT, we designed the protocol of combined transplantation to promote remyelination of the white matter, partially repair the damaged tissue, improve the clinical symptoms and signs, slow down disease progression, and fight chance for HSCT treatment. The postoperative and follow-up results suggest that the clinical manifestations were improved in 5 days to 1 month after transplantation in six $(66.7 \%)$ of the nine patients, including hearing improvement in one patient, visual improvement in two patients, communication and memory improvement in two patients, and even the lesions became smaller in two patients. Although the conditions of the nine patients began progressing 1-3 months after transplantation, these therapeutic effects are still inspiring for such childhood CALD patients. We speculate that allogeneic cells are usually rejected, and some form of immunosuppression should be administered to patients. ${ }^{39}$
Thus, the effects are relatively short. Especially, it was shown previously that transplanted short-lived cells are also capable to provide therapeutic effect. ${ }^{40}$ However, even if the cells survive, they should be probably widely distributed within the CNS, as single injections were shown largely ineffective in other white matter disease - Pelizaeus-Merzbacher disease. ${ }^{41}$ However, the mechanism underlying these effects remains to be further explored. They may be related to neurotrophic factors and myelination brought by the transplanted cells. However, these factors failed to change the NFS in a short time, and long-term follow-up results suggest that the patients still faced rapid disease progression. The short-term therapeutic efficacy of combined transplantation of NPCs and OEC in some cases of this study suggests that there is still room for improvement in the strategies of treatment in the following areas. First, whether or not application of immunosuppressants such as cyclosporin A and FK506 could also reduce the occurrence of graft-versus-host reaction, improve the therapeutic efficacy and prolong the remission duration. Second, whether increasing the number of transplanted cells and frequency of transplantation could improve the therapeutic efficacy and further reduce or reverse the neurological damage and symptoms so as to create the opportunity for HSCT therapy. Finally, whether or not serial transplantation (NPC+OEC transplantation-HSCT-NPC+OEC transplantation) may provide a better choice. Evidence-based medicine has shown that HSCT can decrease the VLCFA concentration and prevent further brain injuries via paracrine peroxidase after entry into the host brain tissue by donor macrophages. However, the repair effect of HSCT is limited for brain tissues where injury has already occurred. First, NPC+OEC transplantation is likely to create opportunities for the following HSCT therapy, which can prevent further white matter damage through correction of bad metabolism condition of peroxidase. Then, the last NPC+OEC transplantation may provide a maximum repair effect on white matter injury and improve the quality of life of ALD patients.

\section{Conclusion}

The preliminary results from this study suggest that a comprehensive prevention strategy of serial and combined transplantation may improve some functions for ALD patients in the short-term, however, long-term effects need further study.

\section{Disclosure}

The authors report no conflicts of interest in this work. 


\section{References}

1. Bezman L, Moser AB, Raymond GV, et al. Adrenoleukodystrophy: incidence, new mutation rate, and results of extended family screening. Ann Neurol. 2001;49(4):512-517.

2. Berger J, Gartner J. X-linked adrenoleukodystrophy: clinical, biochemical and pathogenetic aspects. Biochim Biophys Acta. 2006;1763(12): 1721-1732.

3. Moser HW, Kemp S, Smith KD. Mutational analysis and the pathogenesis of variant X-linked adrenoleukodystrophy phenotypes. Arch Neurol. 1999;56(3):273-275.

4. Moser H, Dubey P, Fatemi A. Progress in X-linked adrenoleukodystrophy. Curr Opin Neurol. 2004;17(3):263-269.

5. Kim JH, Kim HJ. Childhood X-linked adrenoleukodystrophy: clinicalpathologic overview and MR imaging manifestations at initial evaluation and follow-up. Radiographics. 2005;25(3):619-631.

6. Mahmood A, Dubey P, Moser HW, Moser A. X-linked adrenoleukodystrophy: therapeutic approaches to distinct phenotypes. Pediatr Transplant. 2005;9(Suppl 7):55-62.

7. Linnebank M, Semmler A, Kleijer WJ, et al. The cystathionine betasynthase variant c.844_845ins68 protects against CNS demyelination in X-linked adrenoleukodystrophy. Hum Mutat. 2006;27(10):1063-1064.

8. Peters C, Charnas LR, Tan Y, et al. Cerebral X-linked adrenoleukodystrophy: the international hematopoietic cell transplantation experience from 1982 to 1999. Blood. 2004;104(3):881-888.

9. Moser HW, Raymond GV, Koehler W, et al. Evaluation of the preventive effect of glyceryl trioleate-trierucate ("Lorenzo's oil") therapy in $\mathrm{X}$-linked adrenoleukodystrophy: results of two concurrent trials. Adv Exp Med Biol. 544:369-387.

10. Loes DJ, Hite S, Moser H, et al. Adrenoleukodystrophy: a scoring method for brain MR observations. AJNR Am J Neuroradiol. 1994;15(10): 1761-1766.

11. Luan Z, Yin GC, Hu X, et al. Treatment of an infant with severe neonatal hypoxic-ischemic encephalopathy sequelae with transplantation of human neural stem cells into cerebral ventricle. Zhonghua Er Ke Za Zhi. 2005;43(8):580-583. Chinese.

12. Liu K, Li Y, Wang, H, et al. The immunohistochemical characterization of human fetal olfactory bulb and olfactory ensheathing cells in culture as a source for clinical CNS restoration. Anat Rec (Hoboken). 2010;293(3):359-369.

13. Ministry of Public Health, Science and Technology Bureau. Instruction for prepare and clinical application of the aborted human fetuses (91006). Beijing, People's Republic of China: Ministry of Public Health, Science and Technology Bureau; 1991.

14. Dubey P, Raymond GV, Moser AB, Kharkar S, Bezman L, Moser HW. Adrenal insufficiency in asymptomatic adrenoleukodystrophy patients identified by very long-chain fatty acid screening. $J$ Pediatr. 2005;146(4):528-532.

15. Moser HW, Raymond GV, Lu SE, et al. Follow-up of 89 asymptomatic patients with adrenoleukodystrophy treated with Lorenzo's oil. Arch Neurol. 2005;62(7):1073-1080.

16. Miller WP, Rothman SM, Nascene D, et al. Outcomes after allogeneic hematopoietic cell transplantation for childhood cerebral adrenoleukodystrophy: the largest single-institution cohort report. Blood. 2011;118(7):1971-1978.

17. Luan Z, Liu W, Qu S, et al. Effects of neural progenitor cell transplantation in children with severe cerebral palsy. Cell Transplant. 2012;21(Suppl 1): S91-S98.

18. Luan Z, Yin GC, Hu X. Outcomes of human NSC/NPCs transplantation on one infant with severe HIE. Chin J Pediatr. 2005;49(8):580-584.

19. Qu S, Luan Z, Yin G. Effect of human NSC/NPCs transplantation by ventricle on HIE rat model. Chin J Pediatr. 2011;43(8):576-579.

20. A service of the U.S. National Institutes of Health. 2013. Available from: https://www.clinicaltrials.gov/. Accessed September 24, 2015.

21. Selden NR, Al-Uzri A, Huhn SL, et al. Central nervous system stem cell transplantation for children with neuronal ceroid lipofuscinosis. J Neurosurg Pediatr. 2013;11(6):643-652.
22. Shihabuddin LS, Numan S, Huff MR, et al. Intracerebral transplantation of adult mouse neural progenitor cells into the Niemann-Pick-A mouse leads to a marked decrease in lysosomal storage pathology. J Neurosci. 2004;24(47):10642-10651.

23. Givogri MI, Bottai D, Zhu HL, et al. Multipotential neural precursors transplanted into the metachromatic leukodystrophy brain fail to generate oligodendrocytes but contribute to limit brain dysfunction. Dev Neurosci. 2008;30(5):340-357.

24. Taylor RM, Lee JP, Palacino JJ, et al. Intrinsic resistance of neural stem cells to toxic metabolites may make them well suited for cell non-autonomous disorders: evidence from a mouse model of Krabbe leukodystrophy. J Neurochem. 2006;97(6):1585-1599.

25. Neri M, Ricca A, di Girolamo I, et al. Neural stem cell gene therapy ameliorates pathology and function in a mouse model of globoid cell leukodystrophy. Stem Cells. 2011;29(10):1559-1571.

26. Huang H, Chen L, Wang H, et al. Influence of patients' age on functional recovery after transplantation of olfactory ensheathing cells into injured spinal cord injury. Chin Med J (Engl). 2003;116(10):1488-1491.

27. Huang H, Chen L, Xi H, et al. Olfactory ensheathing cells transplantation for central nervous system diseases in 1,255 patients. Zhongguo Xiu Fu Chong Jian Wai Ke Za Zhi. 2009;23(1):14-20. Chinese.

28. Lima C, Pratas-Vital J, Escada P, Hasse-Ferreira A, Capucho C, Peduzzi JD. Olfactory mucosa autografts in human spinal cord injury: a pilot clinical study. J Spinal Cord Med. 2006;29(3):191-203..

29. Mackay-Sim A, Feron F, Cochrane J, et al. Autologous olfactory ensheathing cell transplantation in human paraplegia: a 3-year clinical trial. Brain. 2008;131(Pt 9):2376-2386.

30. Rabinovich SS, Seledtsov VI, Poveschenko OV, et al. Transplantation treatment of spinal cord injury patients. Biomed. Pharmacother. 2003; 57(9):428-433.

31. Ramon-Cueto A, Valverde F. Olfactory bulb ensheathing glia: a unique cell type with axonal growth-promoting properties. Glia. 1995; 14(3):163-173

32. Shi X, Kang Y, Hu Q, et al. A long-term observation of olfactory ensheathing cells transplantation to repair white matter and functional recovery in a focal ischemia model in rat. Brain Res. 2010;1317: 257-267.

33. Cao L, Liu L, Chen ZY, et al. Olfactory ensheathing cells genetically modified to secrete GDNF to promote spinal cord repair. Brain. 2004; 127(Pt 3):535-549.

34. Pastrana E, Moreno-Flores MT, Avila J, Wandosell F, Minichiello L, Diaz-Nido J. BDNF production by olfactory ensheathing cells contributes to axonal regeneration of cultured adult CNS neurons. Neurochem Int. 2007;50(3):491-498

35. Sethi R, Sethi R, Redmond A, Lavik E. Olfactory ensheathing cells promote differentiation of neural stem cells and robust neurite extension. Stem Cell Rev. 2014;10(6):772-785.

36. Wang G, Ao Q, Gong K, Zuo H, Gong Y, Zhang X. Synergistic effect of neural stem cells and olfactory ensheathing cells on repair of adult rat spinal cord injury. Cell Transplant. 2010;19(10):1325-1337.

37. Zhang J, Liu Z, Chen H, et al. Synergic effects of EPI-NCSCs and OECs on the donor cells migration, the expression of neurotrophic factors, and locomotor recovery of contused spinal cord of rats. J Mol Neurosci. 2015;55(3):760-769.

38. Liu SJ, Zou Y, Belegu V, et al. Co-grafting of neural stem cells with olfactory en sheathing cells promotes neuronal restoration in traumatic brain injury with an anti-inflammatory mechanism. J Neuroinflammation. 2014;11:66.

39. Gorelik M, Janowski M, Galpoththawela C, et al. Noninvasive monitoring of immunosuppressive drug efficacy to prevent rejection of intracerebral glial precursor allografts. Cell Transplant. 2012;21(10):2149-2157.

40. Kim H, Walczak P, Kerr C, et al. Immunomodulation by transplanted human embryonic stem cell-derived oligodendroglial progenitors in experimental autoimmune encephalomyelitis. Stem Cells. 2012; 30(12):2820-2829.

41. Gupta N, Henry RG, Strober J, et al. Neural stem cell engraftment and myelination in the human brain. Sci Transl Med. 2012;4(155):155ra137. 


\section{Publish your work in this journal}

The Journal of Neurorestoratology is an international, peer-reviewed, open access online journal publishing original research and review articles on the subject of Neurorestoratology. To provide complete coverage of this revolutionary field the Journal of Neurorestoratology will report on relevant experimental research, technological advances, and clinical achievements. The manuscript management system is completely online and includes a very quick and fair peer-review system, which is all easy to use. Visit http://www.dovepress.com/testimonials php to read real quotes from published authors.

Submit your manuscript here: https:/www.dovepress.com/journal-of-neurorestoratology-journal 